\title{
Quantitative assessment of Critic acid present in various soft drinks available in India.
}

\author{
Anjali Sudhir Puranik \\ Sheth J.N. Paliwala Commerce College, Science and Arts College, Pali-Sudhagad \\ aspuranik9@gmail.com
}

\begin{abstract}
Carbonated and non-carbonated are the two categories of soft/energy drinks are very commonly available. The non -carbonated soft drinks contain citric acid as a major component. In addition, some other acids such as Ascorbic, Malic, Caffeic acid are added in minute quantity as an as anti-oxidants, flavours and preservatives. In the current study the critic content is determined using two parallel methods for the same sample; one is visual titration and another by using $\mathrm{pH}$-metre with combined glass electrode. The overall range for citric acid content is 1.445 to $9.722 \mathrm{~g} / \mathrm{L}$ by visual titration whereas 1.577 to 1.577 by pH metric titration.
\end{abstract}

\section{Introduction:}

Soft drinks have five main subcategories viz bottled water; carbonated soft drinks; dilutables, (squashes, powders, cordials and syrups); fruit juices (100\% fruit juice and nectars (25-99\% juice content) and still drinks (including ready-to-drink (RTD) teas, sports drinks and other noncarbonated products with less than $25 \%$ fruit juice) [1]. Troiano et al. [2] reported that 20 $24 \%$ of energy intake came from beverages. Some soft drinks are formulated to deliver a rapidly assimilated energy boost to the consumer. Soft drinks generally contain soluble sugars, which are easy to administer. To maintain the sour taste, to boost The Kerb cycle, to preserve the soft drink, to add a disinfectant in body, the multitasker component of utmost significance is 'citric acid' [3]. Phosphoric acid is added to cola drinks to enhance the tartness. A few lime tasting carbonated drinks also contain phosphoric acid for the same purpose [1]. Acidity regulators are the food additives used to change or maintain the $\mathrm{pH}$ whereas acidulants are the acids added to confer sour flavours [4]. The Citric acid plays double role as acid regulator as well as acidulant in the drink they contain. Acid like ascorbic acid is a Vitamin as well as an antioxidant. Malic acid, Fumaric acid and tartaric acid provide natural taste to the drink. Caffeic acid is another antioxidant used commonly [5]. Taylor [6] summarized that the components of soft drinks are as follows: water up to $98 \% \mathrm{v} / \mathrm{v}$, carbon dioxide $0.30-60 \% \mathrm{~m} / \mathrm{v}$, acids 0.03 to $0.05 \%$ Sweetener (sugars $7-12 \% \mathrm{~m} / \mathrm{v}$ ), colors (natural or synthetic) 0-70ppm. According to Md Nassiruddin et al,[7 ] the citic acid content in various types of leboos is 0.26 to $1.50 \%$ and Vit C viz Ascorbic acid content is 1.36 to $3.39 \%$, Another study carried out by Peniston et al [8] showed that citric acid in lemon juice and lemon juice concentrate is $0.92 \mathrm{~g} / \mathrm{L}$ and $48.0 \mathrm{~g} / \mathrm{L}$ respectively. While its level in other commercially available juice products was ranging from $1.01-7.44 \mathrm{~g} / \mathrm{L}$. Citrus fruits contain 0.026 to $1.50 \%$ citric acid. Citric acid in energy drinks, juice drinks and soft drinks is found to be $7.3 \mathrm{~g} / \mathrm{L}, 2.79 \mathrm{~g} / \mathrm{L}$ in and $1.76 \mathrm{~g} / \mathrm{L}$ respectively[3 ]. Generally, the concentration of citric acid in beverages and soft drinks commonly found is 
same as in in natural fruits. Citric acid content of the fruits is as follows: orange 1\%, grapefruits $1.5 \%$, and lemon $2.5 \%$. A typical addition of 0.25 to $0.4 \%$ of citric acid is done to enhance flavour and as preservative as declared by European Citric Acid Manufacturers Association (ECAMA) [9]. There are no recommended concentration levels of citric acid in soft drinks; however USA soft and fruit drinks contain varying quantities of the same are $0.131-0.350 \%$ and $0.6-6 \%$ respectively[10].

\section{Materials and Methods:}

1. Various soft drinks bottles were purchased from market. To prepare the analysis sample, the bottled drink is poured in a $250 \mathrm{~cm}^{3}$ borosil beaker and boiled for ten minutes to remove carbon dioxide or nitrogen if used during packing.

2. All the reagents used are of AR grade. Sodium Hydroxide solution is standardised using $0.1 \mathrm{~N}$ $\mathrm{K}-\mathrm{H}$ Phthalate solution. An aliquot of $25 \mathrm{~cm}^{3}$ of sample is titrated with standard $\mathrm{NaOH}$ solution in both methods. Visual titration is done by using Phenolphthalein indicator solution. Similarly, Standard determination is done for Citric Acid.

3. The $\mathrm{pH}$-meter with combined glass electrode is standardised by using the buffer solutions of $\mathrm{pH}=7, \mathrm{pH}=9.2$ and $\mathrm{pH}=4$. The titration of samples and standards was continued till $\mathrm{pH}$ of the titter solution exceeds the $\mathrm{pH}$ value of 10 and remains constant for further additions of titrant.

4. Two types of graphs are plotted in instrumental method. $\mathrm{pH}$ Vs Volume of $\mathrm{NaOH}$ solution added and $\frac{\Delta p H}{\Delta V}$ with volume of $\mathrm{NaOH}$ solution added. The first derivative graph is used to determine the equivalence point whereas the titration curve confirm nature of acid in the soft drink

\section{Results:}

The estimation is done by two different ways to eliminate determinate error:

Running parallel determination and Comparison with standard.

The $\mathrm{pKa}$ values for citric acid are: $p K a_{1}=3.15, p K a_{2}=4.77, p K a_{3}=6.40[11]$. Visual titration gives a single end point corresponding to the third dissociations of citric acid. The indicator phenolphthalein shows colour change between $\mathrm{pH}$ range of 8.2 to 10. During titration with $\mathrm{NaOH}$, this range corresponds to third dissociation. One drop in excess is sufficient to bring colour change at equivalence point of titration. Hence, equivalent weight is one third of the molecular weight of citric acid. Pure citric acid shows only one peak corresponding to third dissociation. Samples containing citric acids result into the graph with similar nature.

Since the other acidic ingredients are neutralised simultaneously, the end point corresponds to the total acid contents instead of specifically citric acid. Molecular weight of citric acid is 192.124 and that of Malic, Ascorbic and caffeic acid are in the same range [14] hence the total acid content is calculated in terms of citric acid as it is done for total hardness of water [15]. Using these stoichiometric relations, the acid contents of soft drinks is calculated. 


\begin{tabular}{|c|c|c|c|}
\hline Sr. No. & Name of drink & $\begin{array}{l}\text { Strength of critic acid } \\
\text { by Visual titration }\end{array}$ & $\begin{array}{l}\text { Strength of citric acid } \\
\text { by } \mathrm{pH} \text { metric titration }\end{array}$ \\
\hline 1 & Maza & 3.100 & 3.153 \\
\hline 2 & Real Mango & 3.757 & 3.731 \\
\hline 3 & Fruity & 3.495 & 3.153 \\
\hline 4 & Slice & 2.628 & 2.522 \\
\hline 5 & Appy & 2.890 & 2.733 \\
\hline 6 & Mirinda & 2.759 & 2.417 \\
\hline 7 & Sting & 4.020 & 3.757 \\
\hline 8 & Limca & 1.655 & 1.682 \\
\hline 9 & Sprite & 1.445 & 1.577 \\
\hline 10 & Nimbooz & 5.386 & 5.413 \\
\hline 11 & Fanta & 2.102 & 1.839 \\
\hline 12 & 7 up & 1.787 & 1.629 \\
\hline 13 & Dawat Jeera & 1.655 & 1.419 \\
\hline 14 & Rio ( Mango) & 2.838 & 2.733 \\
\hline 15 & Rio (Wild Berry) & 2.890 & 2.733 \\
\hline 16 & Lichi & 2.628 & 1.892 \\
\hline 17 & Red Bull & 9.722 & 8.671 \\
\hline 18 & Bubbly Bhai & 3.284 & 3.258 \\
\hline 19 & Dawat Lemon & 3.284 & 3.258 \\
\hline 20 & Mint Monjito & 2.759 & 2.785 \\
\hline 21 & Blaster Jeera & 3.416 & 3.311 \\
\hline 22 & Alofruit Blood orange & 3.810 & 3.836 \\
\hline 23 & Alofruit Kivi & 2.759 & 3.100 \\
\hline 24 & Alo fruit Mosambi & 4.730 & 4.835 \\
\hline 25 & Alo fruit Guava & 2.890 & 2.943 \\
\hline 26 & Pure Citric acid & 2.522 & 2.522 \\
\hline
\end{tabular}

The overall range for total acid content is 1.445 to $9.722 \mathrm{~g} / \mathrm{L}$ by visual titration whereas 1.577 to 8.671 by $\mathrm{pH}$ metric titration. 

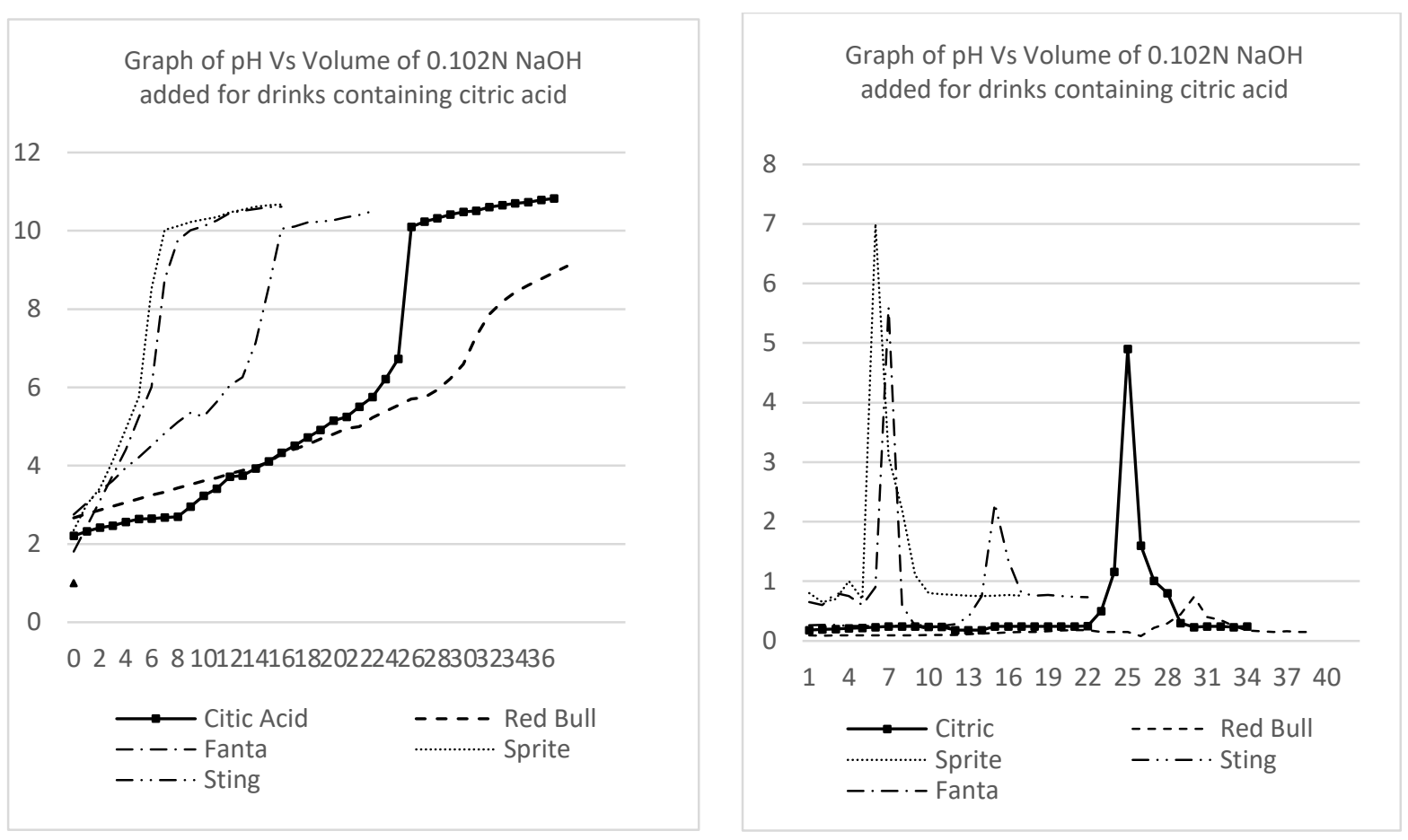

\section{Discussions:}

The acids are usually associated either their salts which sets a buffer system in the sample. Secondly, the flavours, antioxidants, Vitamins etc are either acids or salt which contribute to $\mathrm{pH}$ of sample. The titration when carried out using $\mathrm{pH}$ meter encounters these compounds may result in end point little different than that of volumetric. However, this difference is very small since the concentration of those ingredients is very low. The $\mathrm{pH}$-metry helps to confirm the presence of citric or phosphoric acid from the graph.

This estimation is more valuable since the acid regulators and acidulants are neither mentioned by their names nor is their concentration printed. A common science student would not know the acid content of the drink whereas one can read the composition of a pharmaceutical. There is a numbering system used in Europe for all approved additives which is now adopted and extended internationally by Codex Alimentarius [12]. For example, Phosphoric acid as E330, Acetic acid as E 260 etc. In some countries other than Europe, the letter E is replaced by INS (International numbering system) or somewhere, $\mathrm{E}$ is dropped and simply number is used. The observation table contains the number same as mentioned by manufacturer. The United states Food and Drug administration (FDA) lists these items as 'Generally Recognized As Safe'[13]

\section{Conclusions:}

Using two different methods, classical as well as instrumental, the acid content estimated in ready to consume soft drink is between $3.613 \pm 0.15$ to $24.305 \pm 0.27$ for citric acid and for phosphoric acid containing drinks it is $2.499 \pm 0.07$ to $9.495 \pm 0.35$. There is no upper limit for concentration of citric acid in soft drinks in any guideline in any country. This concentration range is coinciding with that of natural fruit juices rather towards lower range. Since the fruits and fruit juices are perishable, the availability of synthetic drinks is winning the game against 
the natural drinks. The ever-growing popularity of soft drinks is not just for the sake of taste or due to effect of advertisement but also its benefit for health. Quick thirst for refreshing nutrients like citric acid, vitamin C, sugar etc is satisfied by these drinks. However, since they do not contain enzymes, fibre and many micronutrients as available in natural drinks, the soft drinks cannot replace the natural juices.

\section{References:}

1. Roethenbaugh G(2005) Ingredients. In Chemistry and Technology of Soft Drinks and Fruit Juices. Ashurst PR (Eds.), Sheffield Academic Press, England, pp. 15-34.

2. Troiano RP, Briefel RR, Carroll MD, Bialostosky K (2000) Energy and fat intakes of children and adolescents in the United States: data from the National Health and Nutrition Examination Surveys. Am J Clin Nutr 72(5 Suppl): 1343S-1353S.

3. Eid I Brima Annas M. Abbas(2014) Determination of citric acid in Soft drinks, Juice drinks and Energy drinks ISSN: 2321-4902 Volume 1 Issue 6

4. National Soft Drink Association (2003) What's in Soft Drink.

5. Abdeiazmi Sayed and Abdelazimf Abdellati: (2018): The BeveragesAgri Res \&Tech: openAccesJ.2018; 14(5) 555933

6. Taylor RB (2005) Other beverage ingredients. In: Ashurst PR (Ed.), Chemistry and Technology of Soft Drinks and Fruit Juices. Sheffield Academic Press, England, pp. 90-128.

7. M Nassiruddin, M Mahmudul Hasan(2019): Quantitative Analysis of Juice, citric acid, vitamin -C content, sugar levels and sugar acid quantitative relation in some cultivated citrus fruits. ISSN: 2455-4898 Volume 4 Issue 2Page 38-41

8. Krishna Penniston, Stephen Y Nakada (2008): Quantitative assesme t of Citic acid in Lemon Juice,Lime Juice, and Commercially -Avialable Fruit Juice products.(2008) J Endourol : 22(2): 567-570

9. European Citric Acid Manufacturers Association(ECAMA). Citic acid Applications: Soft Drinks and Beverages. (2013) http://www.ecama.org/level_2/applic/softdrinks 1.htm

10. Application of Citric Acid and Citrates in Beverages (2013) www.hawkinswatts.com/doccuments/CitricAcidCitratesinBeverages.pdf

11. Open Library Press Books Appendix: Selected Acid Dissociation Constants at $25^{\circ} \mathrm{C}$

12. CODEX ALIMENTARIUS COMMISSION PROCEDURAL MANUAL. Twenty-fifth edition Joint FAO/WHO Food Standards Programme (2018)

13. FDA (2019) Generally Recognized As Safe (GRAS)

14. PubChem: National Library of Medicine 